\title{
UM ESTUDO SOBRE AS RELAÇÕES DOS PROFESSORES DE CIÊNCIAS DA NATUREZA DAS ESCOLAS PÚBLICAS DE RAFAEL FERNANDES (RN) COM A EDUCAÇÃO AMBIENTAL
}

\author{
Carlos Lenilson Costa ${ }^{1}$ \\ Ayla Márcia Cordeiro Bizerra²
}

Resumo: A escola, enquanto espaço formal de ensino, é o ambiente ideal para oportunizar debates sobre as problemáticas ambientais. Nesse sentido, o objetivo deste trabalho é investigar como a Educação Ambiental e as temáticas ambientais são abordadas pelos docentes das disciplinas de Ciências Naturais das escolas públicas de Rafael Fernandes-RN. Os dados foram coletados por meio de questionário online, os quais indicam que os professores possuem conhecimentos sobre Educação Ambiental, com abordagens restritas à sua formação; e que eles enfrentam dificuldades quanto à ausência de materiais específicos, espaços e recursos financeiros. Assim, os órgãos responsáveis devem oferecer formação e condições favoráveis para a implantação da Educação Ambiental.

Palavras-chave: Formação Acadêmica; Educação Ambiental; Uso de Temáticas Ambientais; Ciências Naturais.

Abstract: The school, as a formal teaching space, is the ideal environment to provide opportunities for debates on environmental issues. The objective of this work is to investigate how Environmental Education and environmental themes are addressed by teachers of Natural Sciences disciplines in public schools in Rafael Fernandes-RN. Data were collected through an online questionnaire, which indicates that teachers have knowledge about Environmental Education, with approaches restricted to their training; and that they face difficulties regarding the absence of specific materials, spaces and financial resources. Thus, the responsible bodies must offer training and favorable conditions for the implementation of Environmental Education.

Keywords: Academic Education; Environmental Education; Use Of Environmental Themes; Natural Sciences.

${ }^{1}$ Instituto Federal de Educação, Ciência e Tecnologia do Rio Grande do Norte. E-mail: carlos.lenilson@outlook.com, Link para o Latttes: http://lattes.cnpq.br/9235695625464329

2 Instituto Federal de Educação, Ciência e Tecnologia do Rio Grande do Norte. E-mail: aylabizerra@gmail.com, Link para o Latttes: http://lattes.cnpq.br/0416876292590430 


\section{Introdução}

A Educação tem se construído, bem como se perpetuado, através dos tempos por meio das interações entre sujeito-sujeito e sujeito-ambiente. Em virtude dessas interações, surge a necessidade de debater os mais diversos temas, assim como, construir relações sociais, econômicas, políticas e científicas. Nessa perspectiva, 0 ato de ensinar no ambiente escolar vai tomando novos rumos quanto à dimensão ambiental, com isso, evidencia-se a necessidade de discussões que se relacionem com as demandas da sociedade, de modo a oportunizar o conhecimento dos fenômenos da realidade, tanto em termos críticos como científicos (CARVALHO, 2017).

Abordar as problemáticas ambientais é contemplar questionamentos atuais e pertinentes para o sujeito e para a sociedade, é refletir a respeito das ações de cada indivíduo em seu ambiente natural ou construído. Por esse motivo, tais debates devem ocorrer nas escolas e se propagarem além delas, pois são assuntos que devem - ou deveriam - ser de interesse de todos (REZENDE; BAMPI, 2019). Propiciar discussões no contexto escolar sobre temas que envolvam o meio ambiente e, principalmente, demonstrar alternativas para agir sobre questões associadas a esses conteúdos são essenciais para construção individual e coletiva de valores sociais, conhecimentos, habilidades, atitudes e competências voltadas para a conservação do meio ambiente (LOURENÇO, 2018).

A Educação Ambiental, no tocante à prática pedagógica, é uma atividade intencional da prática social, que possui caráter formativo para 0 desenvolvimento de relações entre o homem e a natureza, e visa potencializar a atividade humana promovendo atos sociais e éticos ambientais. Sendo assim, a qualificação docente para a Educação Básica deve incluir discussões e ações concretas, as quais viabilizem a prática da Educação Ambiental no contexto escolar quanto aos conhecimentos sistematizados e práticas sociais intencionais, com foco em metodologias e estratégias de ensino transversais e interdisciplinares (CARVALHO, 2017; BRASIL, 2012; CORTES JUNIOR; FERNANDEZ, 2016).

Portanto, o papel da Educação Ambiental não pode ser neutro, acrítico ou restrito a momentos pontuais, pois são temas atuais e fazem parte do contexto social de todos, e na escola, relaciona-se diretamente com as disciplinas das Ciências da Natureza (BRASIL, 2012; MARTINS; SCHNETZLER, 2018). É necessário que neste espaço sejam promovidas discussões que mostrem como a interferência do ser humano está afetando a natureza, e gerem ações que cada um possa realizar para contribuir na melhoria da qualidade de vida. Nesse sentido, surge o questionamento quanto à inserção da Educação Ambiental na prática dos professores de Ciências da Natureza, e no caso deste estudo, aqueles das escolas públicas do município de Rafael Fernandes-RN.

Diante do exposto, o presente trabalho tem o objetivo de investigar como a Educação Ambiental e as temáticas ambientais são abordadas pelos 
docentes das disciplinas de Ciências Naturais (Química, Física, Biologia e Ciências) das escolas públicas do município supracitado.

\section{Educação Ambiental segundo os documentos oficiais}

As discussões em relação à Educação Ambiental em nível global iniciaram em 1972, na Suécia, com a Conferência das Nações Unidas sobre o Ambiente Humano, na qual discutiram com profundidade a inserção das temáticas ambientais no campo educacional. Como desdobramento, a Organização das Nações Unidas (ONU) criou o Programa Internacional de Educação Ambiental (PIEA) com metas e princípios educacionais nesse campo. Em 1977, em uma conferência sobre Educação Ambiental (realizada na cidade de Tbilisi-Geórgia), foram realizados debates que culminaram para a definição de diretrizes, estratégias e ações que são adotadas até os dias atuais no campo educacional (PIRES et al., 2014).

No Brasil, as discussões sobre Educação Ambiental foram intensificadas em termos político e institucionais com a Lei Federal no 9.795/1999 (Política Nacional de Educação Ambiental) e o Decreto Federal no 4.281/2002 (PIRES et al., 2014). A articulação de problemas ambientais deve abranger o âmbito global, nacional, regional ou local, posto que os sujeitos precisam ser formados de modo ativo sobre sua realidade e a Educação Ambiental deve permitir uma formação humanística e democrática, já que as ações de preservação e cuidado são deveres de todos (BRASIL, 1999).

No cenário atual, a Educação Ambiental é entendida como parte integrante dos valores sociais, individuais e coletivos, devendo ser desenvolvida no âmbito formal e informal da aprendizagem. Esse campo educacional necessita "imprimir ao desenvolvimento individual um caráter social em sua relação com a natureza e com os outros seres humanos, visando potencializar essa atividade humana com a finalidade de torná-la plena de prática social e de ética ambiental" (BRASIL, p. 2, 2012). Ela precisa ser trabalhada em todos os níveis e modalidades da educação, contribuindo para a formação de valores, identificação e solução das problemáticas, com o objetivo de estimular a conscientização crítica sobre os problemas socioambientais (BRASIL, 1999).

A Resolução no 2, do Conselho Nacional de Educação, diz que a Educação Ambiental deve ser incorporada ao currículo escolar, de forma dinâmica, integrada e interdisciplinar com as demais disciplinas (BRASIL, 2012). A dimensão ambiental integrada ao currículo escolar oportuniza espaços de conhecimento e interação entre homem-sociedade-natureza, criando condições para novas relações sociais e práticas ambientais (DEMOLY; SANTOS, 2018). Esse documento ainda fala que a inserção dos conhecimentos sobre a Educação Ambiental, na Educação Básica ou Superior, pode ocorrer por meio da transversalidade, mediante temas relacionados ao meio ambiente e à sustentabilidade socioambiental, pela combinação de 
transversalidade ou interdisciplinaridade com os conteúdos dos componentes curriculares (BRASIL, 2012).

Os projetos de cursos de graduação e pós-graduação também devem estar vinculados à Educação Ambiental, porém é facultativo um componente curricular específico. O intuito é promover formação inicial ou continuada dos profissionais em aspectos socioambientais para a atuação docente no âmbito escolar e acadêmico. No entanto, é necessário que as instituições de ensino (básica, técnica ou superior) forneçam, além da capacitação humana, espaços favoráveis para os educadores promoverem a sustentabilidade e a convivência saudável com o meio (BRASIL, 2012).

Atualmente, encontra-se em vigor a Base Nacional Comum Curricular (BNCC), um documento de caráter normativo que tenta articular conteúdos e temas para todas as áreas do conhecimento da Educação Básica. Ela menciona a importância de discussões nas diversas fases, etapas e modalidades da Educação Básica a respeito da sustentabilidade e conscientização socioambiental. Contudo, a ausência do termo Educação Ambiental reduz o papel dessa dimensão na construção de valores políticos, sociais, históricos, atitudinais e culturais para com o meio ambiente (OLIVEIRA; ROYER, 2019; FRIZZO; CARVALHO, 2018; BRANCO; ROYER; BRANCO, 2018).

Segundo Behrend, Cousin e Galiazzi (2018), a Educação Ambiental perdeu espaço no decorrer das etapas de elaboração deste documento, o qual apresenta predomínio de uma visão naturalista e conservacionista. A inserção da Educação Ambiental está limitada às áreas de Ciências da Natureza e Geografia, as abordagens passaram a ter papel secundário e a inclusão das temáticas ficou a critério das instituições sem as devidas orientações (OLIVEIRA; NEIMAN, 2020). Todavia, a introdução da dimensão Ambiental, no espaço escolar, necessita da colaboração entre os entes federados, as entidades gestoras e os profissionais da educação (BRASIL, 2012; BRASIL, 1988).

A Educação Ambiental na BNCC, por sua vez, está restrita a termos como sustentabilidade e conscientização socioambiental, o que acaba ocultando o seu papel no meio escolar, visto que sua essência não é apenas a construção de valores morais, sociais e da conscientização, é necessário que o trabalho deixe de ser momentâneo e pontual, passando a integrar os conteúdos específicos e a promover ações. Nesse intuito, as instituições precisam contribuir na formação de sujeitos críticos e ativos, a reflexão e a ação precisam convergir para a promoção de um ambiente ecologicamente equilibrado e melhor qualidade de vida (OLIVEIRA; ROYER, 2019).

\section{A Educação Ambiental na prática pedagógica escolar}

O ambiente escolar é um espaço que oportuniza estabelecer relações e uma rede de informações para criar condições e possibilidades que incentivem os sujeitos a desenvolverem concepções, habilidades, competências e atitudes

revista brasileira educação ambiental 
e, deste modo, perceberem-se como integrantes do meio ambiente $e$ praticantes de ações ecológica e socialmente corretas (SILVA; SOUZA, 2017). De acordo com Carvalho (2017), a visão socioambiental orienta-se pela racionalidade dos processos interativos entre ser humano, natureza e sociedade, logo, as formas de conceber e praticar a Educação Ambiental no espaço formal ou informal precisam partir da existência das inter-relações entre os seres vivos, os recursos naturais e o ambiente naturalmente equilibrado.

Assumir uma postura socioambiental frente ao trabalho docente é ressignificar o processo de ensino e aprendizagem, e surge como uma maneira de romper a barreira da dicotomia entre sociedade e natureza. Nesse processo, pois, se reconhece a complexidade das problemáticas ambientais, quanto aos aspectos sociais, políticos e culturais construídos ao longo do tempo (CARVALHO, 2017). Ao abordar problemáticas ambientais no âmbito escolar, é importante que elas sejam planejadas considerando as dimensões físicas e biológicas da natureza articuladas às questões sociais, culturais e políticas, posto que, somente dessa forma, a reflexão, o pensamento crítico e as ações socioambientais apropriadas podem ser desenvolvidas (SOUZA et al., 2013; ARAÚJO; DOMINGOS, 2018).

Nessa concepção, as temáticas relacionadas à Educação Ambiental são caracterizadas como temas transversais, dado que são assuntos urgentes a serem debatidos, considerando a realidade dos sujeitos envolvidos. Dessa forma, o contexto social precisa estar agregado aos conhecimentos científicos, promovendo o entendimento e a formação de cidadãos críticos e ativos frente às problemáticas emergentes (PÁTARO; PÁTARO, 2011).

A complexidade ao trabalhar Educação Ambiental exige de o educador abordagens metodológicas que superam a fragmentação do conhecimento, pois as problemáticas ambientais requerem um trabalho educativo sem restrição a uma única disciplina, sendo importante criar abordagens colaborativas com professores de outras áreas (CORCETTI; TREVISOL, 2004). Nesse viés, o conjunto de conhecimentos teóricos, metodológicos e reflexivos para ressignificar a prática docente requer formação inicial e/ou continuada, com discussão de conceitos, estratégias, técnicas e troca de experiências (SILVA; SOUZA, 2017; MARTINS; SCHNETZLER, 2018).

As dificuldades e desafios ao tentar implementar a Educação Ambiental no âmbito escolar estão relacionadas aos assuntos de legislação ambiental, abordagem das problemáticas ambientais de forma transversal, à falta de recursos para realizar atividades de visitação a zoológicos e herbários e parcerias entre instituições, à ausência de espaços para diálogos das práticas em Educação Ambiental, à carência de material didático abordando as temáticas, à falta de orientação pedagógica e cursos de capacitação e de maneiras de inter-relacionar os conteúdos escolares aos temas ambientais (SILVA, 2013; REZENDE; BAMPI, 2019).Sendo assim, é necessário que sejam adotadas medidas que solucionem esses problemas e possam conduzir 0 
trabalho docente ao desenvolvimento de valores, atitudes e competências socioambientais (ASANO; POLETTO, 2017).

Além dos recursos e metodologias, a escola precisa inserir ações construtivas, reflexivas e críticas no seu currículo, pois o papel da instituição não pode estar vinculado a ações pontuais, tais como: oficinas, dias comemorativos ou atividades extraclasse. Consoante Tozoni-Reis (2012, p. 253), "sem uma proposta clara de inserção curricular da EA, ela vem constituindo-se em um tema 'periférico' do currículo escolar, sua inserção tem tido o papel secundário das atividades extracurriculares". É necessária a implementação de uma Educação Ambiental e do trabalho com problemáticas ambientais que considere as relações sociais, tecnológicas, ecológicas, políticas e o desenvolvimento de competências socioambientais.

Contudo, as mudanças precisam ocorrer não apenas do currículo escolar, mas também nos projetos pedagógicos dos cursos, para que os profissionais sejam capacitados quanto às relações entre os conteúdos escolares, as problemáticas ambientais e a sociedade. Nessa perspectiva, os professores precisam de formação, inicial e continuada, a fim de exercerem práticas educativas que formem sujeitos ativos com posturas socioambientais na tomada de decisões ecologicamente corretas (TOZONI-REIS, 2012). No entanto, para que os profissionais ingressem em cursos de capacitação, são necessárias condições de trabalho (carga horária, remuneração, condições físicas e mentais) favoráveis.

Dessa forma, incluir a Educação Ambiental no ensino formal é desafiador, tanto para a escola quanto para o professor, dada a sua complexidade. Todavia, se faz necessário que os assuntos emergentes sobre meio ambiente sejam trabalhados em salas de aula para além de momentos pontuais, considerando as relações existentes entre sociedade e natureza. $E$ esse ensino por meio de temáticas ambientais necessita ser reflexivo e crítico, para tanto, é fundamental que os saberes, advindos das experiências do dia a dia, sejam aprimorados através dos conhecimentos científicos, isso a fim de os envolvidos possam desenvolver atitudes, valores e competências no tocante a preservar e agir corretamente em benefício de um ambiente ecologicamente equilibrado e consciente da importância do uso dos recursos naturais.

\section{Metodologia}

\section{Caracterização da pesquisa}

Este estudo classifica-se como exploratório porque aborda como a Educação Ambiental está sendo trabalhada pelos professores de Ciências da Natureza (Ensino Fundamental II e Médio) das escolas públicas de Rafael Fernandes - RN, reportando uma familiarização com a problemática (PRODANOV; FREITAS, 2013). Quanto aos procedimentos técnicos, ele é classificado como uma pesquisa de campo, pois apresenta informações e/ou conhecimentos a respeito do problema e suas características, se aprofunda 
sobre as questões em estudo (PRODANOV; FREITAS, 2013) e obtêm as informações diretamente com o público pesquisado (GONSALVES, 2001).

Por fim, apresenta uma abordagem qualitativa, cuja finalidade é a compreensão das relações que os docentes possuem com a Educação Ambiental, possibilitando o estudo das ações efetivadas por eles para contemplá-la, tendo como finalidade descrever, compreender e buscar inferências sobre a realidade dos professores que lecionam as disciplinas da área de Ciências da Natureza. De modo geral, a pesquisa qualitativa se preocupa com aspectos reais que não podem ser quantificados, centrando-se na compreensão, análise, interpretação e explicação da dinâmica das relações sociais (SILVEIRA; CÓRDOVA, 2009).

\section{Público da pesquisa}

A presente pesquisa foi desenvolvida com cinco professores que lecionam nas áreas de Ciências da Natureza (Biologia, Física e Ciências) nas escolas públicas de Rafael Fernandes e que atuam com as modalidades do Ensino Fundamental II e Ensino Médio. Todos os envolvidos possuem entre 5 e 25 anos de experiência na área e concordaram com o Termo de Consentimento Livre e Esclarecido (TCLE) de participação voluntária na pesquisa. O município possui 8 Instituições de Ensino ativas e reconhecidas pelo Ministério da Educação, dentre elas uma Escola Municipal e uma Escola Estadual se enquadraram nas etapas de Ensino definidas neste trabalho e todos os professores que lecionavam as disciplinas (até dezembro de 2020) relacionadas às Ciências Natureza foram submetidos ao questionário online.

\section{Instrumentos de Coleta e Análise dos dados}

Para coleta dos dados, utilizou-se o questionário, caracterizado como um instrumento constituído por uma sequência ordenada de perguntas, objetivas e/ou subjetivas, que devem ser limitadas em extensão e finalidade e, principalmente, claras e objetivas quanto às informações que desejam ser levantadas (MARCONI; LAKATOS, 2003).

O questionário foi elaborado por meio da plataforma digital do Google Formulários e compartilhado o endereço eletrônico de acesso com os participantes. Tal instrumento de pesquisa foi dividido em quatro seções: formação; conhecimento e prática sobre Educação Ambiental; relações entre prática docente e temáticas ambientais; e abordagem de temáticas ambientais em suas aulas, as quais são descritas a seguir.

A primeira seção (formação) está relacionada com a formação acadêmica; buscou-se saber em que medida a formação do respondente contemplou aspectos da educação ambiental ou 0 uso de temáticas ambientais. A segunda seção refere-se aos conhecimentos dos docentes e sua atuação prática em relação à Educação Ambiental; procurou-se saber quais conhecimentos, conceitos, ideias e concepções eles possuem sobre essa área, de qual forma ela é contemplada em suas práticas pedagógicas e se a 
instituição oferece algum tipo de apoio. Dessa forma, as duas primeiras seções se aproximam por contemplarem a formação e os conhecimentos que os participantes possuem na área.

A terceira seção diz respeito à prática docente em relação ao uso de temáticas ambientais em sala de aula; buscou-se levantar dados quanto às dificuldades em relacionar conteúdos escolares da sua e de outras disciplinas com as temáticas, e à aprendizagem no tocante se ela é facilitada ou agravada ao trabalhar os conteúdos escolares relacionados às problemáticas ambientais. A quarta seção foi destinada para os professores relatarem o trabalho de uma temática ambiental qualquer, que já foi aplicada ou apenas planejada, quanto ao objetivo, temática contemplada, disciplinas, materiais, procedimentos e avaliação da aprendizagem. Desse modo, as duas últimas seções se aproximam por aludirem a prática docente em si com relação às temáticas ambientais e sua abordagem em sala de aula.

Após a elaboração desse instrumento, foi necessário realizar um préteste, pois esse procedimento possibilitou averiguar as informações que o questionário é capaz de coletar e permitiu corrigir erros quanto a clareza das perguntas, ambiguidade, linguagem complexa e existência de uma sequência lógica na distribuição das perguntas. O pré-teste sempre deve ser aplicado a um público com perfil semelhante ao público-alvo da pesquisa, dado que permite estimar os possíveis resultados e alterar ou acrescentar questões que coletem dados precisos (MARCONI; LAKATOS, 2003).

Para analisar os dados, utilizou-se a técnica de Análise de Conteúdo, conjunto de técnicas utilizadas em pesquisas de abordagem qualitativa ou quantitativa que tem como princípios a seleção, a organização, a categorização e a interpretação das informações relevantes em um estudo, conforme Bardin (2016). Mediante o exposto, pode-se afirmar que a intenção da análise de conteúdo é diagnosticar, inferir e interpretar as comunicações dos sujeitos ou objetos pesquisados, de modo a contribuir para o entendimento de aspectos de determinado grupo seguindo os objetivos definidos.

\section{Procedimento Metodológico}

Para descrição do caminho metodológico utilizado nesta pesquisa, são apresentadas as etapas que foram realizadas.

Etapa 1: Primeiramente, foi realizada uma visita às escolas públicas de Rafael Fernandes - RN participantes desta pesquisa para conversar com as respectivas diretoras. Nesses encontros, foi explicado o objetivo da proposta e solicitados os contatos (telefone celular) dos professores que ensinam as disciplinas Química, Física, Biologia ou Ciências. Mediante o contexto social e de saúde pública enfrentado devido à pandemia da COVID-19 (SARS-CoV-2), o termo de consentimento livre e esclarecido para participar da pesquisa foi apresentado via questionário virtual (https://forms.gle/EfJjUsw2aV6rSSFo6), o qual os professores somente teriam acesso às questões se concordassem com os termos descritos.

revista brasileira educação ambiental 
Etapa 2: Antes da aplicação do questionário com o público-alvo, foi realizado um pré-teste desse instrumento com seis discentes do curso de especialização de Ensino de Ciências Naturais e Matemática que lecionam disciplinas de ciências naturais em escolas públicas ou particulares. O contato com esse público foi realizado via WhatsApp, apresentando a pesquisa quanto aos objetivos e, após a aceitação, foi enviado link do formulário eletrônico (https://forms.gle/hFoQGawkPXv1HKv77).

Etapa 3: Depois de constatado que os dados obtidos no pré-teste apresentaram relação com os objetivos da pesquisa, possibilitando a coleta dos dados requeridos, o formulário eletrônico foi encaminhado para os professores que lecionam Ciências da Natureza (Biologia, Física e Ciências) nas escolas públicas de Rafael Fernandes - RN.

\section{Resultados e discussões}

\section{Formação}

Inicialmente, foi feita uma caracterização com relação à formação a nível de graduação e pós-graduação dos docentes e o tempo aproximado de experiência com disciplinas da área de Ciências da Natureza que condizem com a Educação Ambiental. Os dados obtidos com esse levantamento estão dispostos na Tabela 1.

Tabela 1: Formação inicial, experiência e formação continuada dos professores participantes.

\begin{tabular}{ccccc}
\hline Professor & Gênero & Formação inicial & $\begin{array}{c}\text { Experiência } \\
\text { (Anos) }\end{array}$ & $\begin{array}{c}\text { Formação } \\
\text { Continuada }\end{array}$ \\
\hline P1 & Feminino & $\begin{array}{c}\text { Licenciatura em } \\
\text { Biologia }\end{array}$ & 9 & Sim \\
\hline P2 & Masculino & $\begin{array}{c}\text { Licenciatura em } \\
\text { Biologia }\end{array}$ & 18 & Não \\
\hline P3 & Feminino & $\begin{array}{c}\text { Licenciatura em } \\
\text { Biologia }\end{array}$ & 25 & Não \\
\hline P4 & Masculino & Licenciatura em Física & 6 & Não \\
\hline P5 & Feminino & Licenciatura em Letras & 5 &
\end{tabular}

Fonte: elaborada pelos autores da obra (2021).

Observa-se que a professora P5 não possui formação na área de Ciências da Natureza, porém os cinco anos de atuação na área justificam sua participação na pesquisa. Segundo Tardif (2012), o saber-ensinar e o saberfazer dos profissionais do magistério vão se construindo durante o dia a dia de sua profissão, pois a vivência de peculiaridades e dificuldades enfrentadas ressignifica seu modo de ser e sua prática. Nesse sentido, os saberes 
pedagógicos da professora P5 provém da universidade, já as teorias e conceitos da área podem ter sido assimilados durante sua experiência ao trabalhar com a disciplina de Ciências do $6^{\circ}$ e $7^{\circ}$ ano do Ensino Fundamental.

Segundo o censo da Educação Básica de 2020, as regiões Norte e Nordeste apresentam, nos anos finais do Ensino Fundamental, menor percentual de disciplinas sendo ministradas por professores com formação específica na área. O mapa de densidade estatística (disponível no documento oficial do INEP) mostra que a região do Alto Oeste Potiguar possui percentual em torno de 20,1 a $40,0 \%$ de professores formados e atuando com disciplinas diferentes da sua área (BRASIL, 2021).

Outro aspecto a ser destacado é a ausência da participação de professores de Química, posto que é um componente curricular obrigatório, no entanto, no período de coleta dos dados, a escola Estadual que oferta o Ensino Médio no município não tinha ocupante desse cargo. Isso indica que um professor não habilitado para lecionar a disciplina de química, a está lecionando.

A respeito do aspecto formação continuada, verifica-se que a participante P1 possui formação em Gestão Ambiental e Saúde Pública, reconhecendo que os conhecimentos adquiridos contribuíram em sua prática. Entretanto, tem consciência que esses aprendizados não são suficientes e é necessário pesquisar e buscar novas maneiras que auxiliem sua atuação. Segue a resposta dessa participante quando questionada sobre sua formação inicial/continuada para sua prática docente em Educação Ambiental:

P1 - "Um pouco. As orientações na formação nem sempre condizem com a prática, precisamos sempre adaptar e pesquisar mais em tudo no qual deseja fazer."

Os demais docentes, por sua vez, não possuem formação continuada, porém os participantes $\mathrm{P} 2$ e P3 já participaram de curso de curta duração ou evento na área de Educação Ambiental. Isso demonstra interesse pela área, pois os diálogos compartilhados em cursos de curta duração ou eventos são possibilidades que esses profissionais têm de aproximarem-se dessa área e buscar melhorar sua atuação docente.

Do total de professores participantes, três (P1, P2 e P3) cursaram a disciplina Educação Ambiental ou alguma disciplina que abordava temáticas ambientais. Os três que tiveram esse contato inicial são formados em Licenciatura em Biologia, curso que já oferece visões voltadas para a conservação do meio ambiente em sua própria estrutura curricular. Já o professor (P4) que é formado em física não teve nenhuma disciplina que oferecesse o aporte teórico inicial sobre as temáticas ambientais. Assim, apesar dessa área pertencer às ciências da natureza, é comum a abordagem desses temas estar vinculada ao campo da biologia (TOZONI-REIS, 2012; REZENDE; BAMPI, 2019; ARAUJO; DOMINGOS, 2018). 
Observa-se, também, que os professores possuem um tempo de experiência considerável (variando de 5 a 25 anos) de atuação na área de Ciências da Natureza, deste modo, a dimensão ambiental já deveria ter sido incorporada à sua formação, pois, segundo o Plano Nacional de Educação Ambiental, a perspectiva ambiental deve constar nos currículos de formação de professores em todos os níveis e disciplinas. Ainda no plano de Educação Ambiental, os professores em atividade devem receber formação complementar em suas áreas de atuação no intuito de compreenderem os objetivos e princípios da Educação ambiental (BRASIL, 1999).

Contudo, o contexto educacional brasileiro sofre com dificuldades estruturais e de capacitação humana, sendo que as mudanças iniciais e que irão surtir efeitos na Educação Básica devem começar pelas universidades, capacitando os profissionais formadores de professores, além de superar problemas de infraestrutura, desvalorização da classe, recursos e outros (TOZONI-REIS, 2012). Vale ressaltar que a EA não tem por obrigatoriedade ser um componente curricular específico, a intenção é que os aspectos teóricos e metodológicos sejam inseridos nas disciplinas e que haja um trabalho colaborativo entre as diferentes áreas (BRASIL, 2012).

\section{Conhecimento e prática sobre Educação Ambiental e temáticas ambientais}

Quando tratamos do trabalho docente na perspectiva da Educação Ambiental, é importante saber quais valores, atitudes e competências devem ser desenvolvidos na estrutura cognitiva dos discentes. Nesse sentido, é preciso buscar novos conhecimentos e as habilidades para promover um ensino e aprendizagem que esteja relacionado a preservação e soluções para o equilíbrio ambiental. Ao analisar as respostas dos docentes, observa-se a descrição de conhecimentos sobre Educação Ambiental quanto ao desenvolvimento de visões voltadas para o respeito e a preservação do meio ambiente. Segue algumas dessas falas:

P1: "É a orientação sobre o meio natural ao qual vivemos e os cuidados reservados a ele (preservação do ambiente, resolução de problemas que afetam ou que coloquem em risco o ambiente)"

P3: "É um processo que contribui para que os indivíduos construam conhecimentos, seus valores sociais, habilidades especiais relacionadas com a preservação e conservação do meio ambiente."

Uma parte que se destaca na fala da professora P1 é sobre a resolução de problemas que afetam o meio ambiente, o que corrobora com um dos objetivos da Educação Ambiental que trata da formação de sujeitos ativos para buscar soluções às problemáticas ambientais. Trabalhar na perspectiva de solucionar ou amenizar problemas deixa de ser uma visão puramente naturalista ou conservacionista (concepções de afetividade, sentir a presença da natureza, plantar mudas) e passa a considerar a interação entre homem, 
sociedade e natureza, ponderando os processos políticos, culturais e sociais (CARVALHO, 2017).

Segundo Brasil (2012), a Educação Ambiental deve imprimir nos sujeitos valores, atitudes, habilidades e competências que os possibilitem viver em equilíbrio com a natureza, fazendo o uso responsável dos recursos naturais e preservando o ambiente natural e construído. Dessa forma, ela não pode ser vista como uma atividade neutra, pois envolve atitudes, interesses e visões de mundo, a partir de uma prática pedagógica voltada para as dimensões política, democrática e humanística. Segue algumas das respostas dos professores sobre a importância da Educação Ambiental:

P2: "Sem educação não há preservação e nem consciência da real importância do meio ambiente para a sobrevivência da nossa espécie. Sem ela é cada vez mais difícil manter o equilíbrio de um planeta sadio."

P3: "É importante que o indivíduo passe a ter consciência que desde cedo, precisa cuidar e preservar e que o futuro depende do equilíbrio entre o homem e natureza e do uso dos recursos naturais."

P5: "A partir do momento em que as pessoas tomam conhecimento da importância do ambiente em que vivem e sua preservação para a sobrevivência no planeta, e procura pôr em prática os conhecimentos adquiridos."

Diante o exposto, pode-se observar que os docentes possuem ideais referentes à necessidade de desenvolver, nos discentes, conhecimentos que mostrem as relações entre sociedade-natureza-homem. A atuação pedagógica deve superar os ideais de uma educação baseada somente no amor e na preservação da natureza, é preciso ampliar o olhar sobre quais conhecimentos e relações precisam ser desenvolvidas; esses sujeitos são a geração futura e precisam agir ativamente na preservação, conservação e resolução de problemas de sua realidade local e global (DEMOLY; SANTOS, 2018).

De acordo com a Lei № 9.795/99, a Educação Ambiental é uma dimensão essencial e permanente da Educação brasileira, devendo estar articulada em todos os níveis e modalidades do processo educativo formal e não formal (BRASIL, 1999). Seguem duas das respostas acerca da necessidade em contemplar a Educação Ambiental nas disciplinas de Ciências Natureza do Ensino Médio e Fundamental:

P1: "Sim, educar e sensibilizar nossos jovens para manter e proteger nosso meio ambiente tornando-os cidadãos conscientes."

P4: "Sim. A conscientização e as práticas de preservação ambiental são processos contínuos."

Nesse contexto, a escola precisa ser o lócus de reflexão e ação mediante os efeitos que as alterações realizadas pelo homem causam ao equilíbrio do planeta. Os docentes devem promover, em seus alunos, a formação de cidadãos críticos e conscientes sobre as ações danosas à 
natureza e as consequências que as modificações no ambiente podem causar para eles e para os demais seres vivos. Seguem três das respostas a respeito da abordagem da Educação Ambiental em sala de aula:

P3: "Desenvolvendo ações educativas sobre questões e problemas ambientais como: O desperdício de água, a coleta de lixo, a reciclagem, entre outros, conscientizando sobre a necessidade de proteção e preservação do meio ambiente."

P4: "Na produção de energia elétrica por fontes renováveis...seria um dos pontos abordados que envolve conscientização e educação ambiental."

P5: "Estabelecendo uma relação entre o conteúdo abordado e as questões relacionadas ao meio ambiente."

Pelo exame dessas respostas, observa-se a tendência em relacionar conhecimentos das disciplinas com as problemáticas ambientais. Conforme afirma Corcetti e Trevisol (2004), a prática pedagógica em Educação Ambiental deve orientar os alunos na preservação, conscientização e ideais críticos socioambientais, fazendo o uso de conhecimentos científicos interligados aos conhecimentos de mundo dos discentes. Os Parâmetros Curriculares Nacionais frisam a necessidade de abordar esses temas de forma transversal, buscando interligar os conhecimentos disciplinares aos acontecimentos locais, regionais e globais, mas de preferência que sejam associados à realidade local dos estudantes (BRASIL, 1998).

Tendo isso em vista, faz-se imprescindível que as abordagens dos docentes levem em consideração a indissociabilidade entre problemáticas ambientais e sociedade, de modo que os conhecimentos iniciais dos discentes sejam aprimorados com base em conceitos científicos. Todavia, esse ideal de Educação Ambiental não é tão simples, mas se torna viável quando os profissionais trabalham em colaboração e a instituição oferece apoio pedagógico, materiais didáticos na área e recursos para tal (MARTINS; SCHNETZLER, 2018).

Nesse sentido, o questionário solicitava aos pesquisados que descrevessem um planejamento, que já foi ou não aplicado em sala de aula, considerando as perspectivas ambientais. É de suma importância entender que a aprendizagem em Educação Ambiental não está restrita apenas a integração que se faz entre os conteúdos, é uma dimensão que considera a formação social e científica dos sujeitos, por meio da abordagem de temas urgentes e presentes no cotidiano da escola ou dos próprios sujeitos. A Tabela 2 apresenta os objetivos contemplados nesse planejamento. 
Tabela 2: Objetivos definidos nos planejamentos dos professores.

\begin{tabular}{cl}
\hline Professor & \multicolumn{1}{c}{ Objetivo da aula } \\
\hline P1 & $\begin{array}{l}\text { "Conhecer o processo de compostagem, reconhecendo o reaproveitamento de } \\
\text { materiais, decomposição de determinados produtos e seu tempo de } \\
\text { decomposição e contaminação do solo através de produtos químicos." }\end{array}$ \\
\hline P2 & "Conhecer a diversidade biológica da região na qual a escola está inserida." \\
\hline P3 & "Conhecer algumas consequências da poluição da água." \\
\hline P4 & $\begin{array}{l}\text { "Mostrar os efeitos da mudança climática sobre os agentes polinizadores } \\
\text { (abelhas)." }\end{array}$ \\
\hline P5 & $\begin{array}{l}\text { "Compreender que lixo não é tudo que pode ser descartado, mas reaproveitado, } \\
\text { reutilizado..." }\end{array}$ \\
\hline
\end{tabular}

Fonte: elaborada pelos autores da obra (2021).

Consoante a Tabela 2, constata-se que a professora $\mathrm{P} 1$ busca trabalhar o reaproveitamento de orgânicos para produção de adubo, abordando as etapas da compostagem e evitando a contaminação do solo. Incentivar a participação individual e coletiva, permanente e responsável, na preservação do equilíbrio do meio ambiente é entender a defesa da qualidade ambiental como um valor inseparável do exercício da cidadania (BRASIL, 2012), pois as ações para com o meio ambiente colaboram na melhoria da realidade local do sujeito e de outros cidadãos, já que o descarte inadequado de resíduos pode causar problemas ambientais e de saúde pública.

No procedimento adotado para desenvolver esse objetivo, verifica-se que são passos simples e que os discentes podem adotar essas medidas em seus lares, para reaproveitar os resíduos orgânicos na produção de adubo. A Educação Ambiental visa exatamente que esses saberes e ações desenvolvidas na instituição escolar sejam possibilidades para que os alunos apliquem em seu dia a dia, sendo atividade intencional da prática social (SILVA, 2017).

Já o professor P2 almeja promover o conhecimento sobre a biodiversidade local da instituição escolar, conhecendo os tipos de matas e o bioma da região. Esse objetivo é uma forma de promover o cuidado com a qualidade de vida da comunidade, posto que conhecer sobre a integridade dos ecossistemas permite que esses sujeitos desenvolvam, principalmente, atitudes e valores de preservação e conscientização do meio ambiente natural (BRASIL, 2012).

$\mathrm{Na}$ descrição do procedimento, observa-se que o docente vai realizar uma aula de campo em colaboração com o professor de Geografia. Segundo Martins e Schnetzler (2018), a colaboração entre profissionais contribui no desenvolvimento de práticas que tendem a superar a fragmentação do conhecimento das áreas, permite a troca de saberes e experiências, além da reflexão sobre os problemas emergentes do cotidiano escolar.

A professora $\mathrm{P} 3$, por seu turno, visa trabalhar as formas de poluição da água, a abordagem pode estar voltada às ações humanas, quanto ao descarte incorreto de aparelhos eletrônicos, remédios, plásticos, pilhas e baterias, ou à 
falta de saneamento básico, com esgotos a céu aberto ou ausência de tratamento de excrementos humanos. É interessante que a docente trabalhe os fatores que estão intrinsecamente relacionados à realidade local da escola ou de alguma comunidade próxima, demonstrando as ações que podem ser adotadas para resolver ou amenizar esses problemas. Consoante a constituição federal, todos têm direito ao ambiente ecologicamente equilibrado de uso comum, individual ou coletivo, e é dever do poder público e da coletividade preservá-lo para as gerações futuras (BRASIL, 1988).

Enquanto o objetivo do professor P4 é mostrar as influências das mudanças climáticas para os agentes polinizadores (Abelhas), o que permite compreender como as ações humanas afetam outros seres vivos e as futuras consequências para a própria humanidade, já que os agentes polinizadores (abelhas e outros insetos) estão relacionados à produção de frutas e flores, além da preservação da biodiversidade. Sendo assim, pode-se ver um respaldo em desenvolver a compreensão integrada do meio ambiente em suas múltiplas e complexas relações, a fim de fomentar novas práticas sociais e de produção e consumo (BRASIL, 2012).

No tocante ao docente $\mathrm{P} 5$, este propõe a construção de conhecimentos relativos ao descarte adequado e reaproveitamento de resíduos produzidos pelos seres humanos. Assim, pode-se verificar uma abordagem que se enquadra nos três erres (3R) da sustentabilidade, com a intenção de trabalhar os conceitos de reduzir, reutilizar e reciclar. Segundo Brasil (2012), a Educação Ambiental deve ser contemplada em abordagens curriculares que enfatizam a natureza como fonte de vida e a relacione à saúde, ao consumo, ao trabalho para construir uma sociedade ambientalmente justa, sustentável e equilibrada.

Cabe ressaltar que os professores P3, P4 e P5 restringiram a descrição do procedimento à citação de técnicas de ensino, materiais e instrumentos que seriam utilizados no intuito de alcançar os objetivos. Entende-se que é viável o uso desses meios e recursos didático-pedagógicos para a execução das propostas de ensino, porém, é significativo que, em seus planejamentos, existam descrições objetivas sobre os passos necessários a fim de executar a intervenção. Caso o planejamento seja compartilhado com outros profissionais sem as etapas a serem seguidas, é possível que a proposta não possa ser colocada em prática ou, em relação a momentos que exigem conhecimentos disciplinares de outras áreas, não fique entendível para o professor que não é da área.

Ademais, os caminhos delineados para executar esse planejamento e as interações estabelecidas entre conceitos científicos e conhecimentos de mundo dos estudantes serão determinantes na ressignificação do senso comum e na construção de valores, atitudes e ações críticas para com o meio ambiente natural e construído. Esses objetivos definidos pelos professores somente poderão contribuir para a formação de sujeitos socioambientais e críticos se forem pensados, portanto, mediante abordagens com metodologias ativas, temas transversais ou interdisciplinar, os saberes em sua área de formação e a 
aquisição de conceitos científicos de outras áreas (SILVA; SOUZA, 2017; SANTANA; ARAÚJO, 2021; CORTES JUNIOR; FERNANDEZ, 2016).

Nesse trabalho com temas da Educação Ambiental, é importante que sejam estabelecidas relações entre as diferentes áreas, ampliando os debates em suas múltiplas dimensões. Além do meio ambiente ser um tema transversal, ele tem a tendência de ser interdisciplinar, pois não é um objeto de estudo exclusivo de um campo disciplinar (ARAUJO; DOMINGOS, 2018). Nesse sentido, as intervenções com temáticas ambientais envolvem 0 engajamento de todos da instituição (professores, equipe pedagógica) na sua construção e realização, tendo como objetivo a formação de cidadãos reflexivos, críticos e ativos quanto aos aspectos ambientais do seu cotidiano (SILVA; SOUZA, 2017).

Verifica-se, ainda, que todos os cinco profissionais entendem a avaliação da aprendizagem como um processo contínuo, no entanto, é imprescindível que tenham critérios pré-determinados a serem avaliados, já que na avaliação é necessário saber se os discentes possuem os saberes sobre o tema, os conhecimentos escolares e a efetividade das relações entre as experiências do cotidiano e dos conhecimentos científicos adquiridos.

Nessa perspectiva, é necessário considerar, no processo de ensino e aprendizagem, a intencionalidade de desenvolver atitudes, valores e habilidades para a sustentabilidade socioambiental, bem como relações entre homem-natureza-sociedade e ações que podem ser adotadas para convivência saudável e da qualidade de vida, além das competências e habilidades para as áreas do conhecimento envolvidas (CARVALHO, 2017; BRASIL, 2012; BRASIL, 1999).

Quando questionados a respeito das orientações por parte das coordenações pedagógicas das escolas, os professores P1, P3, P4 e P5 relataram que ocorre planejamento de feira de Ciências, propostas de ensino que se inter-relacionam com outras disciplinas, projetos e sugestões de atividade práticas. O professor $\mathrm{P} 2$ disse que não existem orientações por parte da coordenação pedagógica da escola.

É de suma importância que a instituição trabalhe em conjunto para planejar e executar trabalhos voltados à Educação Ambiental. A coordenação pedagógica da escola e os órgãos superiores (Secretarias Municipais, Estaduais e Ministério da Educação) precisam mobilizar ações que capacitem os docentes para atuarem na formação de cidadãos com responsabilidades socioambientais. O desenvolvimento de projetos, feiras de Ciências, atividades práticas que proporcionem habilidades, mudanças de atitudes e valores para com a natureza somente pode ocorrer quando os profissionais têm a capacidade de incorporar novos conceitos, metodologias e técnicas de ensino que viabilizem o trabalho didático (TOZONI-REIS, 2012; SILVA; SOUZA, 2017).

Nesse viés, a Escola necessita assumir posturas que superem 0 desenvolvimento de atividades pontuais quanto à Educação Ambiental. As 
atividades comemorativas no dia do meio ambiente ou no Dia da Árvore e a feira de Ciências são momentos válidos, mas as instituições não podem restringir sua atuação a essas datas. As problemáticas ambientais se fazem presentes todos os dias, a falta de saneamento, o lixo descartado inadequadamente, o consumo exacerbado de produtos, a emissão de poluentes no ar, o desmatamento, as queimadas, entre outras atitudes inadequadas, não cessam seus efeitos prejudiciais ao meio ambiente. As posturas de cuidado, preservação e ações ecologicamente corretas necessitam de uma presença ativa no dia a dia dos estudantes (PIRES et al., 2014).

\section{As potencialidades e dificuldades em trabalhar Educação Ambiental e temáticas ambientais}

Além das propostas sugeridas pelos docentes, buscou-se entender que outras abordagens temáticas são estabelecidas em suas práticas diárias, quais conteúdos e problemáticas ambientais eles costumam abordar, a receptividade dos alunos com esses temas, as dificuldades de aprendizagem e as dificuldades dos profissionais em desenvolver temas ambientais relacionando a sua ou outras áreas.

A quantidade de temáticas ambientais que podem ser relacionadas ao ensino de Ciências é vasta e diversificada, logo entende-se que para os professores relatarem todas seria algo inviável. Por isso, foram dispostos alguns objetos de estudo que possuem forte relação com a área de Ciências da Natureza, sendo atuais e urgentes de discussão no ambiente escolar. Nessa questão, os docentes podiam classificar os objetos em 4 categorias: já trabalhei (1), planejo trabalhar (2), nunca trabalhei (3) e não tem relação com a minha área (4). Parece contraditório a última categoria, já que todas as temáticas são relacionadas ao meio ambiente, mas é essa visão dos professores que se queria ter, se eles são capazes de perceber esses objetos de estudo em sua área de atuação. A seguir, a Figura 1 apresenta os resultados obtidos.

Conforme verifica-se na Figura 1, os professores P2, P4 e P5 são os que mais trabalharam temáticas ambientais em suas práticas. $\mathrm{O}$ professor $\mathrm{P} 2$, formado em Biologia, tem uma abordagem diversificada em suas aulas, só não trabalhou com a temática de resíduos sólidos; as temáticas trabalhadas pelo participante $\mathrm{P} 4$, formado em física, tendem a ter relação com os assuntos da disciplina, como eletromagnetismo, ondas, óptica, eletricidade, força e trabalho; e a participante P5, formada em letras, apresenta a tendência de trabalhar tópicos relacionados a tipos de poluição. Os docentes P1 e P3 foram os que menos indicaram temáticas abordadas em sala de aula, porém planejam incluir os demais temas não mencionados em sua ação docente. 


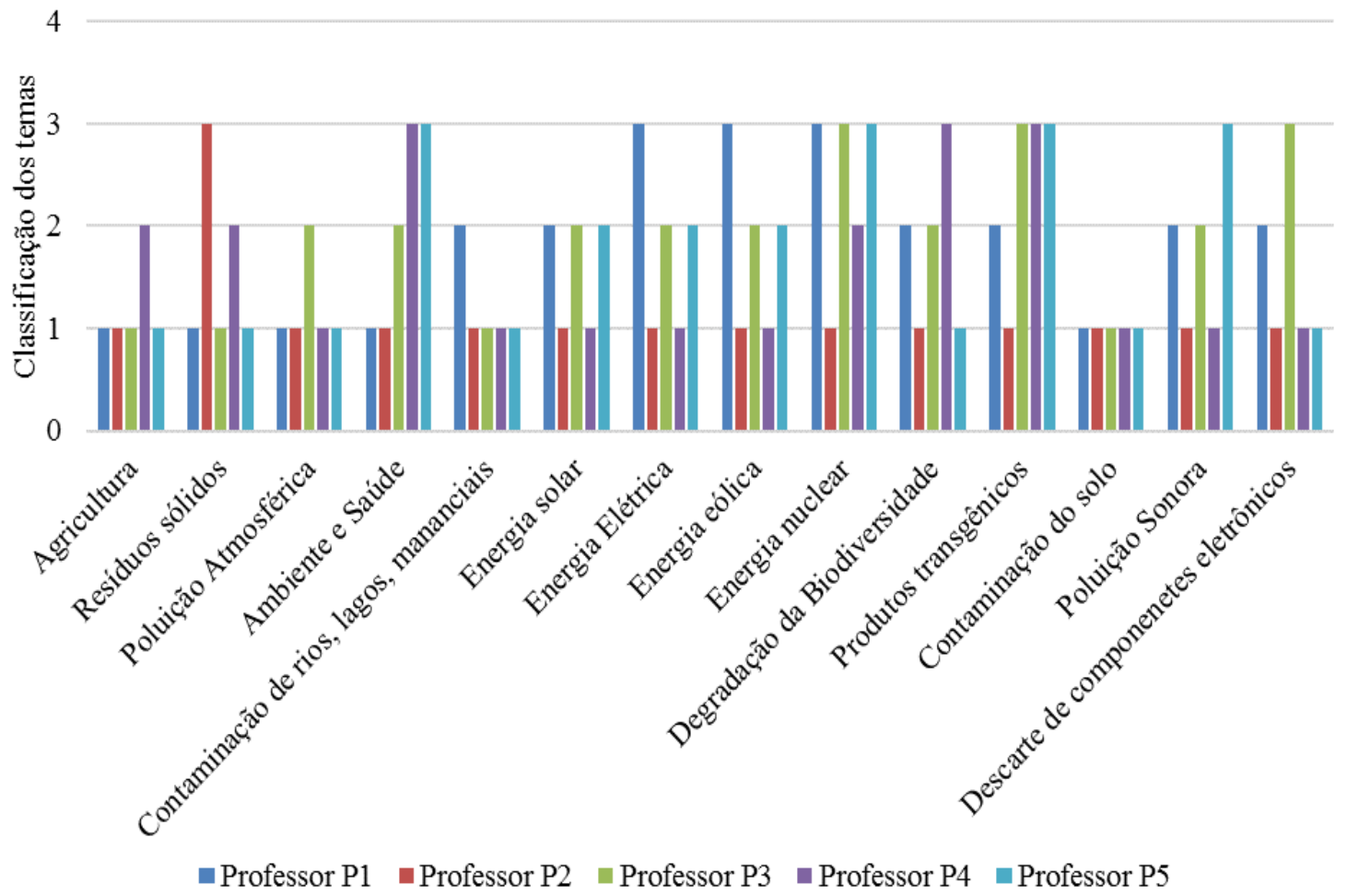

Figura 01: Temáticas ambientais que os professores já trabalharam, planejam trabalhar, nunca trabalharam e não tem relação com minha área.

Fonte: elaborada pelos autores da obra (2021).

A tendência dos assuntos relacionados ao meio ambiente é articular diferentes campos do conhecimento, além de se apresentar como um tema urgente a ser discutido, considerando as dimensões científicas, sociais e políticas (WENCESLAU; SILVA, 2017). Todavia, dadas as dificuldades de infraestrutura, recursos, materiais específicos e formação (inicial e continuada) dos profissionais, o trabalho didático-pedagógico tende a estabelecer relações que estejam restritas a sua área de formação, pois dá a eles a sensação de segurança quanto ao aporte teórico que será usado nas discussões sobre o tema abordado. No entanto, as problemáticas sobre meio ambiente mostramse favoráveis a transitar por vários campos do conhecimento.

Os procedimentos e as metodologias adotadas para a realização das atividades com as temáticas ambientais são fatores cruciais para um trabalho docente pautado na formação de sujeitos críticos e reflexivos. Os processos envolvendo o ensino da educação ambiental e de temáticas ambientais, até então, necessitam de aprimoramentos, a fim possibilitar aos profissionais a capacidade em compreender as complexidades dos temas, pois ir além de sua área de formação exige saberes e capacitação. Existem desafios e dificuldades ao trabalhar os conhecimentos sistematizados com a realidade social dos discentes, mas é com base no uso dos saberes científicos e das implicações 
sociais que se pode compreender os fenômenos do mundo e desenvolver as habilidades de pensar e agir (SANTANA; ARAÚJO, 2021).

Mediante 0 uso de temáticas ambientais, indagou-se aos profissionais a respeito das dificuldades enfrentadas e, a esse respeito, observou-se que elas são relativas e individuais, visto que envolvem questões de capacitação inicial e continuada, apoio da instituição, tempo de planejamento, aprofundamento teórico na área, dentre outros fatores. A Tabela 3 expõe as respostas dos participantes.

Tabela 3: Dificuldades relatadas ao inserir as temáticas ambientais em suas práticas.

\begin{tabular}{|c|c|}
\hline Professor(a) & Dificuldades \\
\hline $\mathrm{P} 1$ & "A grande dificuldade é custear alguns projetos e práticas." \\
\hline $\mathrm{P} 2$ & $\begin{array}{l}\text { "Tempo de planejamento, material concreto para fazer aulas práticas e } \\
\text { recursos para aulas de campo." }\end{array}$ \\
\hline P3 & $\begin{array}{l}\text { "Falta de materiais didáticos, falta de espaço físico para realização de } \\
\text { atividades práticas." }\end{array}$ \\
\hline P5 & $\begin{array}{l}\text { "As dificuldades sempre existem, mas buscando soluções por } \\
\text { orientações pedagógicas, conversando com colegas ou mesmo pe } \\
\text { a gente consegue superá-las." }\end{array}$ \\
\hline
\end{tabular}

Fonte: elaborada pelos autores da obra (2021).

Considerando o exposto na Tabela 3, constata-se que o participante P2, formado em Biologia, reconhece a importância do planejamento e dos recursos financeiros para abordagens com temáticas ambientais, pois cita que das dificuldades enfrentadas há o tempo que precisa dedicar ao plano e os recursos para aulas de campo. Enquanto a professora P3, também formada em Biologia, disse que sofre com dificuldade de espaços apropriados para aulas experimentais, bem como de materiais específicos para o trabalho com a Educação Ambiental e temáticas ambientais. Cabe ressaltar que esses são os docentes participantes da pesquisa com maior tempo de experiência no ensino de disciplinas da área de Ciências da Natureza que condizem com a Educação Ambiental, 18 e 25 anos respectivamente.

As dificuldades no contexto educacional estão presentes em todas os níveis e modalidades, e não é diferente ao trabalhar com temáticas ambientais e formação de sujeitos socioambientais, a infraestrutura, os recursos, os materiais e a capacitação são ferramentas necessárias que implicam no fazer docente (SILVA, 2013; REZENDE; BAMPI, 2019).

Nesse contexto, é de suma importância que os órgãos competentes (ministério e secretarias) supram essas e outras dificuldades existentes na Educação. A inserção da Educação Ambiental precisa superar a ideia de atividade extraclasse ou momentos pontuais no currículo escolar. Segundo Asano e Poletto (2017) e Carvalho (2017), a escola é um espaço privilegiado para que os sujeitos se conectem com os problemas urgentes, atuais e dividam experiências, além de possibilitar a formação de cidadãos com valores, atitudes e com potencial para agirem em prol de um ambiente social e ecologicamente correto. O trabalho com a Educação Ambiental e suas problemáticas é uma 
nova linguagem na tentativa de compreender a vida e a complexidade dos saberes sistematizados (DEMOLY; SANTOS, 2018).

Entende-se as problemáticas ambientais como temas complexos, tanto para os docentes quanto para os discentes; no seu ensino, há momentos que exigem saberes de várias áreas, podendo dificultar a aprendizagem dos educandos. Nesse sentido, questionou-se os professores sobre as dificuldades dos alunos em aprender conteúdos escolares quando relacionados a temas ambientais. A tabela 04 apresenta as dificuldades relatadas:

Tabela 4: Dificuldades dos alunos em aprender conteúdos escolares quando relacionados a temas ambientais.

\begin{tabular}{ll}
\hline Professor(a) & Dificuldade que os professores analisam nos alunos \\
\hline P1 & "Eles não estão acostumados a visualizar a prática ambiental em relação a \\
& $\begin{array}{l}\text { disciplina, além da disponibilidade de tempo e transporte dos que moram no } \\
\text { Sítio. A falta dessa prática faz com que eles rejeitem de início." }\end{array}$ \\
\hline P2 & "Não vejo maiores dificuldades; as que existem demandam mais da boa \\
& vontade em estudar, como demais conhecimentos." \\
\hline P3 & "Está relacionado à falta de conhecimento sobre os temas ambientais. Falta \\
& de material de pesquisa."
\end{tabular}

Fonte: elaborada pelos autores da obra (2021).

Verifica-se que a inserção eventual de práticas da dimensão ambiental causa, no início, certa rejeição mediante o novo modo de ensino e aprendizagem. Isso reafirma a necessidade de mudança do currículo escolar por uma prática integrada às problemáticas urgentes e atuais, com metodologias que favoreçam o trabalho docente em promover mudanças de atitudes, valores e respeito com a natureza (TOZONI-REIS; 2012).

Outro fator é o contexto social desses sujeitos, que interfere em sua rotina de estudos e no acesso aos materiais necessários para a aprendizagem. Araújo e Domingos (2018) sugerem que, ao lidar com sujeitos de um contexto social que passam por dificuldades socioeconômicas, é pertinente trabalhar a Educação Ambiental com base nessa realidade, já que o papel pedagógico da EA não é neutro, ao contrário é transformador e emancipador.

As metodologias e técnicas de ensino usadas pelos docentes interferem no estímulo desse aluno com o novo conhecimento, até mesmo pela própria complexidade do tema. Por essa razão, ao introduzir essas abordagens, é interessante que o profissional mescle as novas metodologias com as habituais a fim de que não cause frustração no alunado. Fazer o uso de metodologias CTS apoiadas no diálogo é uma das maneiras para incluir os debates sobre as temáticas ambientais (CORREA; BARROS; PEREIRA, 2020). Dependendo do contexto social, o acesso primário para pesquisas é por meio do livro didático; e este, ao realizar um tratamento pontual e naturalista da Educação Ambiental, dificulta a aquisição de saberes dos discentes, assim como o planejamento e a ação dos docentes (BONOTTO; SEMPREBONE, 2010; COUTINHO; RUPPENTHAL; ADAIME, 2019). 
Assim sendo, apesar das dificuldades de ensino e aprendizagem enfrentadas, é fundamental que os trabalhos com a inserção da Educação Ambiental e suas problemáticas continuem em prática. É a partir dos diálogos com os colegas de profissão, das experiências em sala de aula e da busca por novos conhecimentos e metodologias que ocorre a ressignificação da prática docente, permitindo aprimoramentos dos métodos utilizados e colaborando para o saber-fazer e o saber-ser (TARDIF, 2012). Além do mais, as habilidades e competências que os docentes desenvolvem nesse percurso refletem no processo de ensino e aprendizagem, posto que contribui para a formação de sujeitos socioambientais, com ideais de respeito e preservação para um ambiente ecologicamente equilibrado.

\section{Conclusões}

Com base nos dados expostos, observou-se que a prática em Educação Ambiental e temáticas ambientais é adotada pelos professores das escolas públicas da cidade de Rafael Fernandes, RN. No entanto, foi possível verificar que ainda há uma atuação voltada para momentos pontuais, e que os professores tendem a utilizar abordagens mais restritas à sua área de formação. Essas circunstâncias são influenciadas por dificuldades e desafios impostos pelos espaços escolares, visto que a prática docente, baseada na complexidade das problemáticas socioambientais, não é algo simples em ser desenvolvida, requer esforços coletivos das instituições e órgãos superiores a fim de superar as adversidades existentes.

Constatou-se, ainda, que 4 dos 5 profissionais não passaram por capacitações e os espaços disponíveis na escola sofrem com problemas de infraestrutura, recursos financeiros e materiais específicos. Esses são fatores complicadores na Educação Ambiental, pois o trabalho com temas transversais exige dos profissionais habilidades em estabelecer relações entre conhecimentos científicos e os fenômenos locais ou globais que interferem na vivência dos discentes, tarefa esta que demanda saberes específicos, dedicação, planejamento e espaços apropriados para executar as ações.

Ressalta-se, contudo, que as inferências realizadas nesta pesquisa foram todas baseadas nos relatos dos professores participantes por meio de questionário online, logo, não é possível realizar análises aprofundadas das habilidades, competências, valores e saberes socioambientais desses profissionais, bem como a utilização disso em seu processo de ensino, nem tão quanto pode-se avaliar se o ensino e a aprendizagem ocorrida nas aulas colaboram para a formação de discentes críticos e ativos ambientalmente.

Portanto, entende-se que, para a inclusão dos princípios e objetivos da Educação Ambiental e a sistematização das problemáticas ambientais com os conhecimentos científicos, é preciso que ocorram mudanças no currículo escolar e que a formação de professores abranja a aquisição de saberes e metodologias na intenção de consolidar essa prática. 
Deste modo, apesar da regulamentação por Leis e Decretos, a inclusão de temáticas ambientais ainda é incipiente nos espaços escolares, fazendo-se necessário e urgente que as entidades responsáveis promovam espaços, com estrutura física e humana, para o desenvolvimento de ações didáticopedagógicas, as quais possibilitem a concretização das temáticas sobre meio ambiente no âmbito escolar com a finalidade de educar para a conscientização socioambiental, construindo pensamento crítico acerca das relações entre homem-natureza-sociedade.

\section{Referências}

ARAUJO, M.I.O.; DOMINGOS, P. Perspectiva Teórico-Metodológica da Educação Ambiental na escola. Pesquisa em Educação Ambiental, São Paulo, v. 13, n. 1, p. 182-195, jun. 2018.

ASANO, J.G.P.; POLETTO, R.S. Educação Ambiental: em busca de uma Sociedade Sustentável e os desafios enfrentados nas Escolas. Caderno Pedagógico, Lajeado, v. 14, n. 1, p. 92-102, jan. 2017.

BARDIN, L. Análise de conteúdo. 1.ed. São Paulo: Edições 70 Lda, 2016. 280 p.

BARROS, A.J.S.; LEHFELD, N.A.S. A pesquisa e a iniciação científica. In: BARROS, A.J.S.; LEHFELD, N.A.S. Fundamentos de Metodologia Científica. 3. ed. São Paulo: Pearson Prentice Hall, 2007. p. 81-97.

BEHREND, D.M.; COUSIN, C.S.; GALIAZZI, M.C. Base Nacional Comum Curricular: o que se mostra de referência à educação ambiental. Ambiente e Educação, Rio Grande, v. 28, n. 2, p. 74-89, 26 nov. 2018.

BONOTTO, D.M.B.; SEMPREBONE, A. Educação ambiental e educação em valores em livros didáticos de ciências naturais. Ciência \& Educação, Bauru, v. 16, n. 1, p. 131-148, fev. 2010.

BRANCO, E.P; ROYER, M.R.; BRANCO, A.B.G. A abordagem da Educação ambiental nos PCNs, nas DCNs e na BNCC. Nuances: estudos sobre Educação, Presidente Prudente, v. 29, n. 1, p. 185-203, abr. 2018.

BRASIL. Constituição (1988). Constituição da República Federativa do Brasil. Brasília, DF: Diário Oficial da União, 05 out. 1988. 496 p.

BRASIL. Instituto Nacional de Estudos e Pesquisas Educacionais Anísio Teixeira (INEP). Censo da Educação Básica 2020: notas estatísticas. Brasília, DF: INEP, 2021. 27 p.

BRASIL. Lei no 9.795, de 27 de abril de 1999. Dispõe sobre a educação ambiental, institui a Política Nacional de Educação Ambiental e dá outras providências. Lei № 9.795, de 27 de abril de 1999. Brasília, DF: Diário Oficial da União, 27 abr. 1999. Disponível em: $<$ http://www.planalto.gov.br/ccivil 03/leis/19795.htm>. Acesso em: 28 set. 2019. 
BRASIL. Ministério da Educação. Base Nacional Comum Curricular. Brasília, 2018. 595 p.

BRASIL. Secretaria de Educação Fundamental. Parâmetros curriculares nacionais: apresentação dos temas transversais. Brasília: MEC/SEF, 1998. 436 p.

BRASIL. Resolução no 2, de 15 de junho de 2012. Estabelece as Diretrizes Curriculares Nacionais para a Educação Ambiental. Resolução № 2, de 15 de junho de 2012. Brasília, DF: Diário Oficial da União, 18 jun. 2012. Seção 1.

CARVALHO, I.C.M. Educação ambiental: a formação do sujeito ecológico. São Paulo: Cortez Editora, 2017. 236 p.

CORCETTI, M.L.; TREVISOL, M.T.C. A escola, o currículo e os temas transversais. Espaços Pedagógicos, Passo Fundo, v. 11, n. 2, p. 28-46, dez. 2004.

CORREA, W.A.; BARROS, H.L.B.V.; PEREIRA, A.S. O tratamento de água como tema potencial no Ensino de Química e sua contribuição no processo de for. Revista de Ensino de Ciências e Matemática, São Paulo, v. 11, n. 4, p. 275-292, 22 jul. 2020.

CORTES JUNIOR, L.P.; FERNANDEZ, C. A Educação Ambiental na formação de professores de Química: estudo diagnóstico e representações sociais. Química Nova, São Paulo, v. 39, n. 6, p. 748-756, jul. 2016.

COUTINHO, C.; RUPPENTHAL, R.; ADAIME, M.B. Estimulando a formação do sujeito ecológico em alunos de Ensino Fundamental: contribuições dos livros didáticos de ciências. Revista de Ensino de Ciências e Matemática, São Paulo, v. 10, n. 3, p. 79-92, 21 jun. 2019.

DEMOLY, K.R.A.; SANTOS, J.S.B. Aprendizagem, Educação e Escola: modos de en-agir na experiência de estudantes e professores. Ambiente e Sociedade, São Paulo, v. 21, n. 1, p.1-20, 10 jul. 2018.

DIAS, J.S.; LIMA, T.L. Concepções e metodologias para promoção e difusão da bioenergia: uma experiência educativa na escola pública. Revista Brasileira de Educação Ambiental, São Paulo, v. 13, n. 3, p. 284-298, 30 set. 2018.

FRIZZO, T.C.E.; CARVALHO, I.C.M. Políticas públicas atuais no Brasil: o silêncio da educação ambiental. Revista Eletrônica do Mestrado em Educação Ambiental, Rio Grande, v. 1, n. 1, p. 115-127, 26 nov. 2018.

GONSALVES, E.P. Escolhendo o percurso metodológico. In: GONSALVES, E.P. Conversas sobre Iniciação à Pesquisa Científica. Campinas: Alinea, 2001. p. 61-75.

LOURENÇO, J.C. Educação Ambiental. In: LOURENÇO, J.C. Educação Ambiental na Prática. Campina Grande: Independente, 2018. p. 254-418. Ebook. 
MARCONI, M.A.; LAKATOS, E.M. Técnicas de pesquisa. In: MARCONI, M.A.; LAKATOS, E.M. Fundamentos de metodologia científica. 5. ed. São Paulo: Atlas, 2003. p. 201-213.

MARTINS, J.P.A.; SCHNETZLER, R.P. Formação de professores em educação ambiental crítica centrada na investigação-ação e na parceria colaborativa. Ciência e Educação, Bauru, v. 24, n. 3, p. 581-598, jan. 2018.

OLIVEIRA, E.T.; ROYER, M.R. A Educação Ambiental no contexto da Base Nacional Comum Curricular para o Ensino Médio. Interfaces da Educação, Paranaíba, v. 10, n. 30, p. 57-78, nov. 2019.

OLIVEIRA, L; NEIMAN, Z. Educação Ambiental no âmbito escolar: análise do processo de elaboração e aprovação da base nacional comum curricular (bncc). Revista Brasileira de Educação Ambiental, São Paulo, v. 3, n. 15, p. 36-52, 21 maio 2020.

OLIVEIRA, M.S. et al. A importância da Educação Ambiental na escola e a reciclagem do lixo orgânico. Revista Científica Eletrônica de Ciências Sociais Aplicadas da Eduvale, Jaciara, v. 5, n. 7, p.1-20, nov. 2012.

PÁTARO, C.S.O.; PÁTARO, R.F. Temas transversais e o trabalho com projetos. Revista Espaço Acadêmico: uma experiência nas séries iniciais do ensino fundamental, Maringá, v. 11, n. 127, p. 48-55, dez. 2011.

PIRES, B.S. et al. Educação Ambiental: conceitos e práticas na gestão ambiental pública. Rio de Janeiro: Inea, 2014. 52 p.

PRODANOV, C.C.; FREITAS, E.C. Metodologia do trabalho científico: métodos e técnicas da pesquisa e do trabalho acadêmico. 2. ed. Novo Hamburgo: Freevale, 2013. 277 p.

REZENDE, F.S.S.L.; BAMPI, A.C. Práticas Pedagógicas em Educação Ambiental na Educação Básica: dificuldades e potencialidades da inserção da temática nas escolas. Educação Ambiental em Ação, Novo Hamburgo, v. 17, n. 67, p. 1-31, maio 2019.

SANTANA, D.B.; ARAÚJO, M.L.F. Educação científica e educação ambiental. Revista Electrónica de Enseñanza de Las Ciencias: aproximações na prática docente, [S. L.], v. 20, n. 1, p. 26-48, jan. 2021.

SILVA, M.A.; SOUZA, A.R.E. Ensino da Educação Ambiental no cotidiano do espaço escolar. Revista de Educação da Universidade Federal do Vale do São Francisco, Petrolina, v. 7, n. 13, p. 112-116, ago. 2017.

SILVA, M.L. A educação ambiental no ensino superior brasileiro: do panorama nacional às concepções de alunos (as) de pedagogia na Amazônia. Revista Eletrônica do Mestrado em Educação Ambiental, Rio Grande, volume especial, p. 18-33, mar. 2013.

SILVEIRA, D.T.; CÓRDOVA, F.P. A pesquisa científica. In: GERHARDT, T.E.; SILVEIRA, D.T. (Org.). Métodos de Pesquisa. Porto Alegre: UFRGS, 2009. p. 31-42. 
SOUZA, G.S. et al. Educação Ambiental como ferramenta para o manejo de Resíduos Sólidos o cotidiano escolar. Revista Brasileira de Educação Ambiental, São Paulo, v. 8, n. 2, p. 118-130, 10 fev. 2014.

TARDIF, M. O saber dos professores em seu trabalho: saberes, tempo e aprendizagem do trabalho no magistério. In: TARDIF, M. Saberes docentes e formação profissional. 14. ed. Petrópolis, RJ: Vozes, 2012. p. 56-72.

TOZONI-REIS, M.F.C. Educação Ambiental na Escola Básica: reflexões sobre à prática dos professores. Revista Contemporânea de Educação, Rio de Janeiro, v. 7, n. 14, p. 243-255, dez. 2012.

WENCESLAU, M.E.; SILVA, F.C.T. Temas transversais ou conteúdos disciplinares? Cultura, cidadania e diferença. Interações, Campo Grande, v. 18, n. 4, p. 197-206, dez. 2017. 